\title{
Age-Related Cellular Proliferation at the Vitreoretinal Juncture
}

\author{
D. McLEOD, P. S. HISCOTT and I. GRIERSON \\ London
}

\begin{abstract}
Summary
Clinical and pathological features of non-vascularised epiretinal membranes are reviewed with special attention to focal epimacular tractional lesions in the elderly. The role of immunohistochemistry in elucidating the nature of component cells of complex epiretinal membranes is emphasised. Clinicopathological correlation establishes the 'fibroglial membrane' as the causative lesion of age-relate'd epimacular traction. The pathogenesis of this process is discussed, including relevant animal models, and chronic inflammation and ischaemia (rather than acute posterior vitreous detachment) are implicated. Vitrectomy and epimacular membrane peeling results in significant visual improvement in most patients.
\end{abstract}

The formation of a cellular epiretinal membrane (ERM) in the posterior part of the fundus, with subsequent contraction and exertion of tangential traction on the retina, is an important problem in the elderly. Such focal fibrocellular proliferations represent part of the spectrum of so-called 'non-vascular proliferative extraretinopathies', ${ }^{1,2}$ the most extreme degrees of which constitute massive periretinal proliferation ${ }^{3}$ or proliferative vitreoretinopathy (PVR), ${ }^{4}$ with extensive membranes in the peripheral (as well as the posterior) fundus and beneath (as well as upon) the retina. Senile epimacular proliferations generally have less severe visual consequences in comparison with the vascularised submacular proliferations of senile disciform degeneration, but are of particular interest since definitive surgical treatment is a vailable for the more severe lesions. As in disciform degeneration, however, the precise pathogenesis of epiretinal cellular proliferation has yet to be clearly established.

\section{Clinical Spectrum of Focal Epiretinal Proliferation}

\section{Severity Grading}

Variations in the clinical picture principally reflect the location, the extent and particularly the contractile activities of ERMs. The following subgroups are arbitrary, but help to maintain etymological simplicity, accuracy and consistency.

(a) Simple Reflective Lamina (SRL):

A glistening, shifting or glinting 'light-reflex' or a diffuse cellophane-like shagreen may be observed incidentally during ophthalmoscopic examination of the macula..$^{5,6}$ The term 'simple' implies that there is no associated effect on the underlying retina nor detectable visual consequences, i.e. the ERM appears to be non-contractile and there is no significant absorption, dispersion or undue reflection of incident rays. Where the involved retinal area is small, the presence of an ERM may be easily overlooked.

From The Surgical Vitreoretinal Unit, Moorfields Eye Hospital and The Department of Pathology, Institute of Ophthalmology, London.

Correspondence to: Mr. D. McLeod, F.R.C.S., Moorfields Eye Hospital, City Road, London EC1V 2PD. 
(b) Surface Wrinkling Retinopathy (SWR): This is characterised by ophthalmoscopically visible changes affecting the innermost part of the retina underlying and adjacent to a contractile ERM. Fine wrinkles or striations of the retinal surface radiate (or otherwise emanate) from an 'epicentre' of ERM contraction in the form of a pucker or pleat. ${ }^{5}$ The ERM itself is frequently very focal and may or may not be ophthalmoscopically identifiable; when extensive, the ERM may have the appearance of 'crinkled cellophane'.5.7. Strictly speaking, SWR implies a contraction process with very limited consequences both structurally and symptomatically. However, although patients with striations passing through the fovea and normal acuity have been reported, ${ }^{9.10}$ we have never observed an asymptomatic SWR lesion with a foveal epicentre.

\section{(c) Full-thickness retinal folding (FTRF):}

This is defined ophthalmoscopically not only by the undulations of the retinal surface but also by the effects of tangential traction on deeper retinal structures up to and including the whole thickness of the retina. Thus, FTRF implies an ERM-contraction process which is more severe and/or more widespread in distribution than that of SWR. The classical sign is abnormal tortuosity of the terminal branches of retinal vessels and a 'drawing together' of the superior and inferior major temporal vascular arcades. ${ }^{5.6}$ Other signs include focal accumulations of axoplasmic debris ${ }^{6.11}$ (implying mechanical or ischaemic obstruction of axoplasmic transport in the retinal nerve-fibre layer), small haemorrhages, fatty exudates, and retinal oedema (whether 'cystoid' or in the form of 'outer retinal shagreen'). ${ }^{12}$ Although absence of fluorescein leakage was originally cited as a differential feature of ERMs compared with other types of maculopathy ${ }^{8}$ an irregular pattern of dye staining is seen in the more severe lesions, ${ }^{5.10}$ especially those resulting from thick opaque ERMS. ${ }^{13}$ The essential folding of the retina is often hidden beneath an opaque ERM so that the true consequences of ERM-contraction may be revealed only at the time of surgical removal of the ERM; $;^{12}$ in some cases, however, the fovea is demonstrably dragged or ectopic, and in extreme instances the retina is frankly involved in localised traction retinal detachment (TRD). Full-thickness tearing of the retina is a rare consequence of such ERM contraction; nevertheless, lamellar and (rarely) full-thickness macular holes may occur, ${ }^{5}$ though these must be distinguished from 'pseudo-holes' ${ }^{14}$ which represent exaggerated cystic changes in the underlying retina. ${ }^{15}$ The ERM itself rarely contains any biomicroscopically-identifiable blood vessels, may show varying degrees of opacification, may be pigmented ${ }^{16}$ and may show partial spontaneous avulsion from the retinal surface (Fig. 1a).

The visual consequences of FTRF lesions depend, of course, on their site (macular or extramacular) and severity; eyes with fluorescein leakage tend to have more marked visual loss. However, the patient's complaints are not necessarily strictly proportionate to the severity of the lesion; metamorphopsia with preserved acuity may be more troublesome than generalised blurring of vision. Obstruction of the light pathway to the retina by an opaque ERM contributes insignificantly to visual loss.

This severity grading (SRL, SWR and FTRF including TRD) does not necessarily comply with all previous literature on the subject; for example, the term SWR is frequently applied to symptomatic lesions. However, diminished vision and metamorphopsia imply a degree of distortion of the outer retina ${ }^{5.13}$ (whether by oedema or folding) so the term SWR would appear to be inappropriate in most cases. Nevertheless, a given degree of ERM contraction may have variable clinical consequences, e.g. an ERM causing large radiating full-thickness retinal folds ("starfold') in a rhegmatogenous detachment may have almost imperceptible tractional effects when the retina is reattached by scleral buckling and break-closure.

\section{Aetiological Classification}

ERMs have been classified according to the clinical circumstances in which they arise (notwithstanding the identical ophthalmoscopic consequences and often similar appearances of ERMs in each aetiological subgroup). 

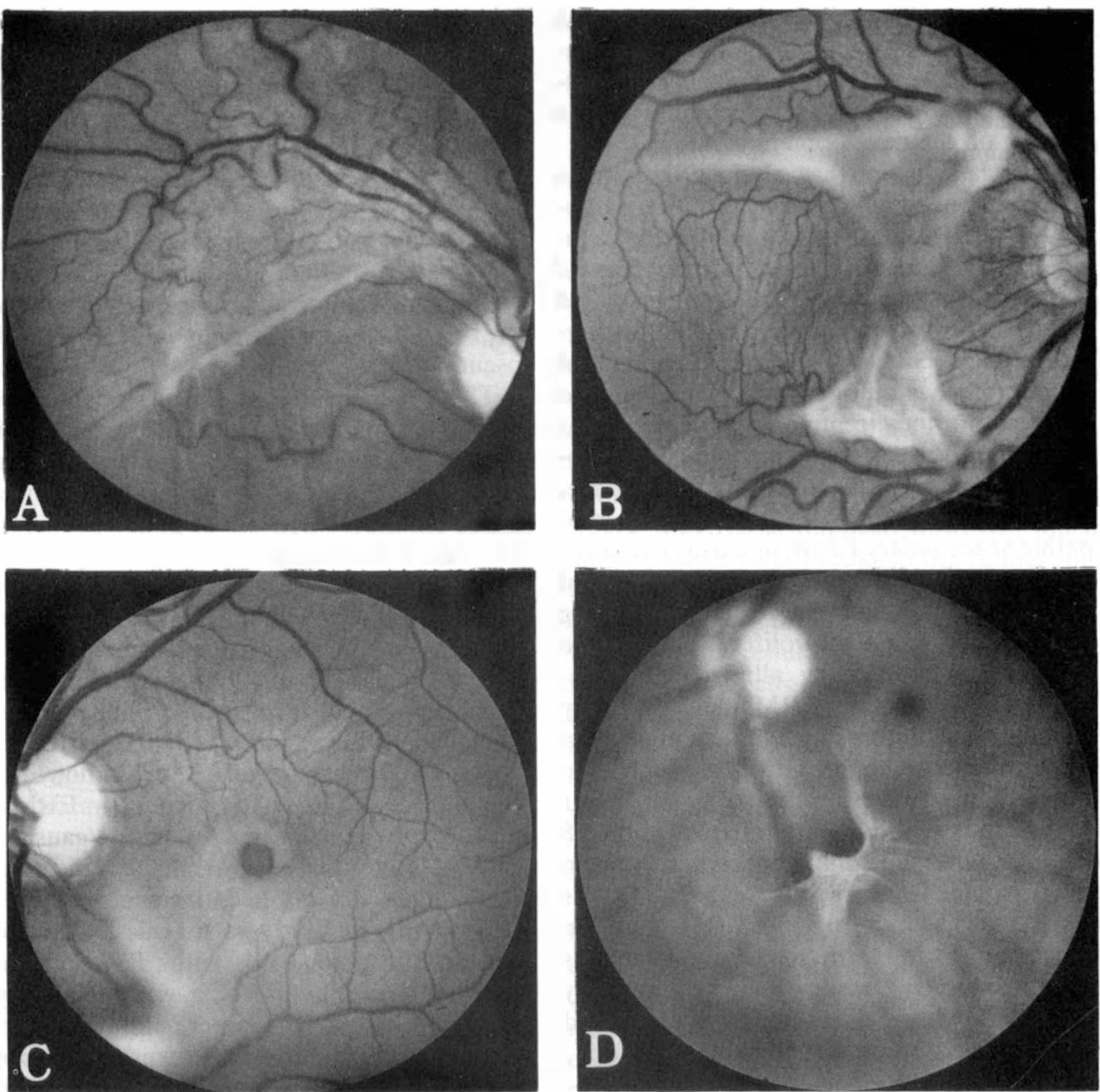

Fig. 1. Fundus photographs:

(a) epimacular membrane showing partial spontaneous avulsion

(b) avulsed epimacular membrane within detached vitreous cortex

(c) full-thickness macular hole after spontaneous avulsion of contractile epimacular membrane reducing vision from $6 / 36$ to $4 / 60$

(d) same eye as (c) showing membrane on detached vitreous face.

(a) Idiopathic ERM:

ERMs are classified as 'idiopathic' if there is no associated ocular abnormality thought to be of aetiological significance (other than posterior vitreous detachment), and no defined retinopathy from coexistent systemic disease, e.g. from systemic hypertension, arteriosclerosis, diabetes mellitus, etc.

(b) Secondary ERM:

This term infers that coexisting or preceding ocular disease had a bearing on the development of the ERM, e.g. retinal vascular occlusion (e.g. retinal branch vein occlusion), diabetic retinopathy, retinal vasculitis (e.g. Eales' disease, sarcoidosis), uveitis (e.g. pars planitis, endophthalmitis), vitreous haemorrhage, trauma, peripheral nodular telangiectasis, ${ }^{17}$ tapeto-retinal degenerations, ${ }^{18}$ etc.

(c) Iatrogenic ERM:

This term infers that surgical intervention 
undertaken prior to recognition of an ERM (especially diathermy, cryopexy, photocoagulation or other procedures in the treatment of a retinal tear or detachment) had a bearing on the development of the ERM.

This classification has obvious limitations which will no doubt persist until the pathogenesis of ERM formation is more clearly elucidated. ERMs associated with untreated retinal breaks, for example, may be classified as either secondary or idiopathic ${ }^{19}$ furthermore, since ERMs are part of the natural history of rhegmatogenous detachment, to what extent does treatment of a retinal tear subsequently associated with epimacular proliferation represent an irrele vant coexistence, a mere provocation of a predisposing idiopathic or secondary ERM ${ }^{2}$ or a truly causative relationship? Nevertheless, it is a useful means of subdividing cases when considering other aspects of ERM proliferation, e.g. the severity-grading already alluded to. Thus, eyes with idiopathic ERMs are generally affected visually to a much lesser extent than those with secondary or iatrogenic ERMs. In various clinical series, ${ }^{6,10}$ approximately 85 per cent of eyes with idiopathic ERMs had 6/18 vision or better with only 2 per cent with vision less than $6 / 60$. Conversely, severe visual loss is more typical of iatrogenic ERMs ${ }^{20,21,22}$ (in which context the term 'macular pucker' was first introduced),${ }^{20}$ while eyes with secondary ERMs often have visual loss from associated pathology, e.g. retinal oedema or ischaemia.

\section{Vitreous Interrelationships}

Clinically, SRL, SWR and FTRF lesions may occur with or without associated posterior vitreous detachment (PVD). A high incidence (80 per cent) of complete PVD was reported at diagnosis in Wise's classic report of 150 idiopathic ERMs, and residual attachments between the ERM and vitreous were reportedly rare. ${ }^{6}$ However, detailed examination of vitreoretinal interrelationships in the posterior pole is frequently difficult and, while opinions contrary to those of Wise have prevailed for many years, ${ }^{5.7,8}$ a recent study using sophisticated biomicroscopy (utilising the El Bayadi-Kajiura lens) has provided interesting new data. ${ }^{23}$ Of the 250 eyes with idiopathic ERMs studied, 23 per cent had no PVD, 62 per cent had complete PVD and the remaining 15 per cent had partial PVD of which the majority $(29 / 250=11.6$ per cent $)$ were macular vitreomembranous attachments. The latter group (exhibiting possible dynamic vitreoretinal traction in addition to tangential static retinal traction) had more fluorescein leakage and exaggerated visual loss compared with the other groups. Similarly, vitreomembranous adhesion has been noted to be a frequent feature of ERMs with pseudo-holes. ${ }^{15}$

There are no equivalent statistics for secondary and iatrogenic ERMs, although these generally arise in the context of complete PVD.

\section{Age-Relationship}

There are no clinical demographic surveys available for idiopathic ERMs, but the agedistribution of cases on clinical presentation or discovery demonstrates a clear-cut relationship with advancing years ${ }^{6.10}-95$ per cent of patients are over 50 years of age and 75 per cent over 60 years of age. There are no really comparable statistics for secondary ERMs; while many ocular pathologies 'causing' ERMs are age-related (e.g. branch vein occlusion), others are not (e.g. trauma, vasculitis and uveitis). Similarly, iatrogenic ERMs are particularly associated with PVD-related tears and detachments which, while especially a problem of elderly ( 85 per cent of patients with iatrogenic ERMs being over 50 years of age in the series of Tanenbaum et al.,${ }^{20}$ ) also include younger patients such as myopes. Thus, in a recent surgical report, the median age at surgery of patients with idiopathic ERMs was 69 years compared with 57 years for those with secondary and iatrogenic ERMs. ${ }^{15}$ Nevertheless, Lobes and Burton ${ }^{22}$ reported a linear, statistically-significant increase in the risk of iatrogenic ERM formation with advancing years from 30 years of age onwards.

\section{Clinical Course}

Eyes with idiopathic ERMs tend to have a remarkably stable clinical course from the time of diagnosis ${ }^{5.68 .10}$ (that is, except in Michigan). ${ }^{15}$ Approximately 90 per cent of the ERMs reported by Sidd and colleagues ${ }^{10}$ 
showed no change in ophthalmoscopic appearance during follow up. Many of these eyes also maintained the same level of vision, though there was a tendency to slight visual deterioration (without change in ophthalmoscopicappearance), presumably from continuing secondary changes within the retina, e.g. from chronic macular oedema. Of the remaining 10 per cent of idiopathic ERMs, most showed increasing tractional effects on the retina and progressive deterioration of vision with time, while occasional eyes showed improvement in vision and less traction. Such improvement may be a consequence of either separation of a residual vitreomembranous attachment or spontaneous peeling of the ERM from the retinal surface, 5,7 often in conjunction with PVD (Fig. 1b). On rare occasions, however, spontaneous ERM peeling is complicated by macular hole formation and further visual loss (Fig. 1c, d).

The clinical course of secondary ERMs is often obscured or overwhelmed by the associated pathology; the presence of an epimacular membrane behind a vitreous haemorrhage, for example, may be undetectable ultrasonically and electrophysiologically, but may seriously limit visual improvement after eventual spontaneous or surgical clearance of the haemorrhage. Iatrogenic ERMs characteristically have a rapidly progressive clinical course, though some successfully-treated total detachments, complicated by macular pucker, may nevertheless show gradual visual improvement with time reflecting macular retinal reattachment. ${ }^{20}$

\section{Histopathological Spectrum and Clinicopathological Correlation}

\section{Severity Grading:}

Current concepts of senile epiretinal proliferations derive from study of autopsy eyes, enucleated globes and ERM specimens obtained after surgical peeling of ERMs.

\section{(a) Simple ERM:}

Cellular ERMs with no detectable tractional effects on the underlying retina are a frequent incidental finding on the posterior retina of enucleated eyes. ${ }^{24}$ The ERMs are 'simple' not only in respect of absent consequences but also in respect of their cellular content which, by light microscopy with special (though nonspecific) glial stains, ${ }^{25}$ by electron microscopy identifying characteristic cytofilaments, ${ }^{24,26}$ and by specific immunohistochemical staining for glial fibrillary acidic protein (GFAP), ${ }^{27}$ are virtually exclusively glial in origin. The glial cells appear to derive from the underlying retina and reach their extraretinal destination by both migration and cell-division, traversing the inner limiting lamina (ILL) of the retina through 'surface breaks' or 'ILL dehiscences' (Figs. 2, 3). Surface breaks are generally less than $50 \mu$ in diameter and appear to be preferentially located over retinal blood vessels where the ILL is thinnest; however, much larger paravascular breaks in the retinal surface after PVD have also been described..$^{28}$

Epiretinal glia in simple ERMs show great variations in cellular arrangement from a small nidus of cells overlying a surface break to a compact orderly structure comprising multiple layers of glial-cell processes and few cell-bodies. $^{24,26}$ Intracellular inclusions suggesting phagocytosis by epiretinal glia may be seen (Fig. 3). The glial cells on the vitreal surface of a fully-established ERM form a 'pavement' with overlapping interdigitating borders and microvilli which are best appreciated by scanning electron microscopy ${ }^{26,27}$ (Figs. 4, 5). The specific types of glia present in ERMs cannot be defined with certainty, even by electron microscopy or immunohistochemistry. Foos has advocated the role of accessory glia in this process, ${ }^{24}$ but Muller cells also appear to be implicated especially in the immediate vicinity of the surface breaks. ${ }^{26,29}$ Immunostaining for GFAP highlights the continuity established between the epiretinal and retinal glia, the latter (including both accessory glia and Muller cells) sometimes showing enhanced immunoreactivity in eyes with simple ERMs. ${ }^{27}$

Clinicopathological correlation of a simple ERM has been provided by Bellhorn and colleagues ${ }^{29}$ who showed that a glial membrane which was predominantly only one cell thick could give rise to the glistening light-reflex characterising the SRL lesion clinically. This confirms the remark of Wolter correlating SRL (the 'glial chagrin') with astroglial pro- 

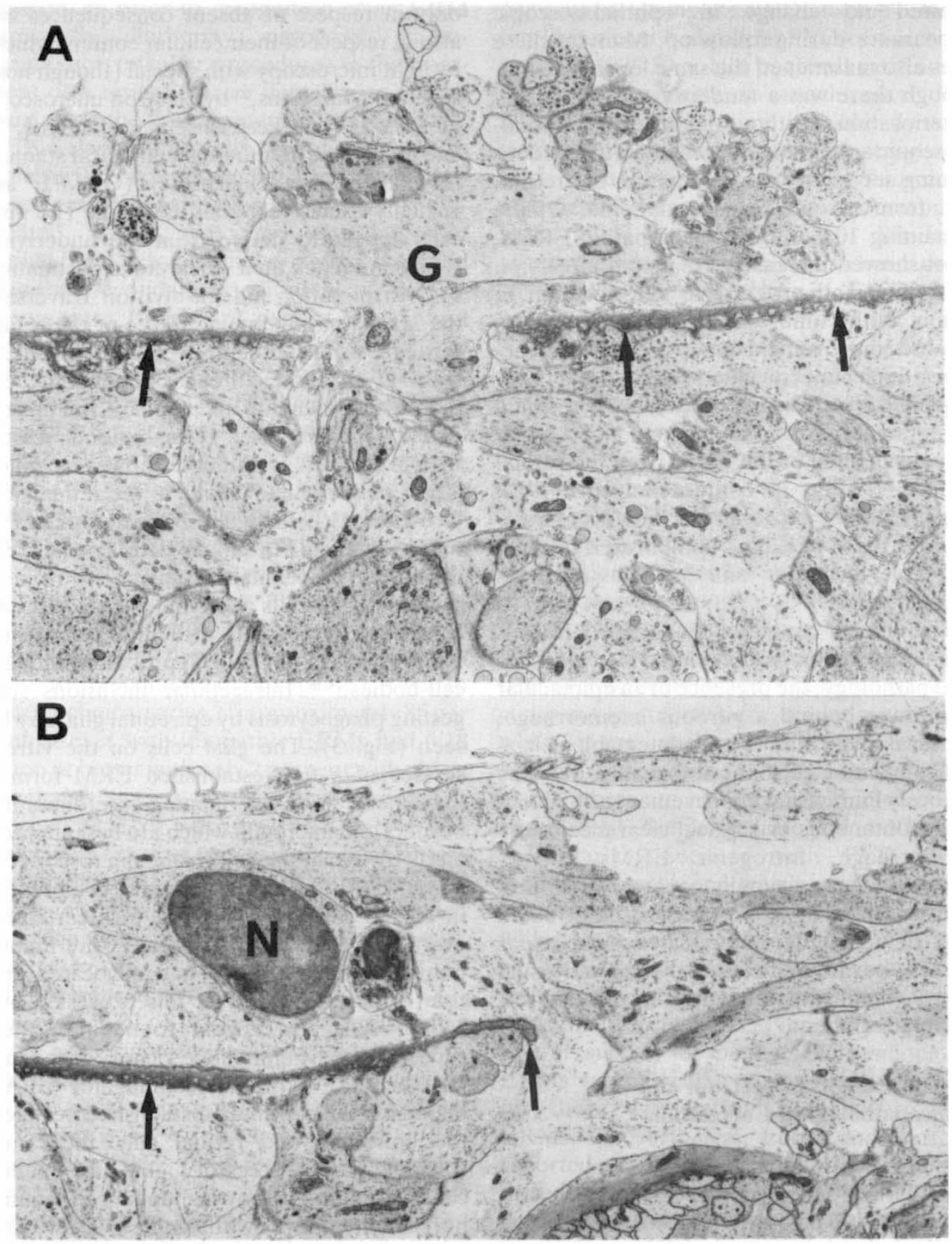

Fig. 2. Transmission electron micrographs of a simple idiopathic epiretinal membrane:

(a) glial elements $(G)$ protruding through a break in the inner limiting lamina (arrows). $\times 6,500$

(b) part of epiretinal membrane in continuity with retina through a large break in the inner limiting lamina (arrows) over a retinal vessel; cell nucleus $(N) . \times 3,200$

liferation on the retinal surface, ${ }^{25}$ and is further exemplified in retinitis pigmentosa. ${ }^{18,30}$ (b) Surface Wrinkling Retinopathy (SWR): Foos has shown that focal (or occasionally more extensive) areas of wrinkling of the sur- 


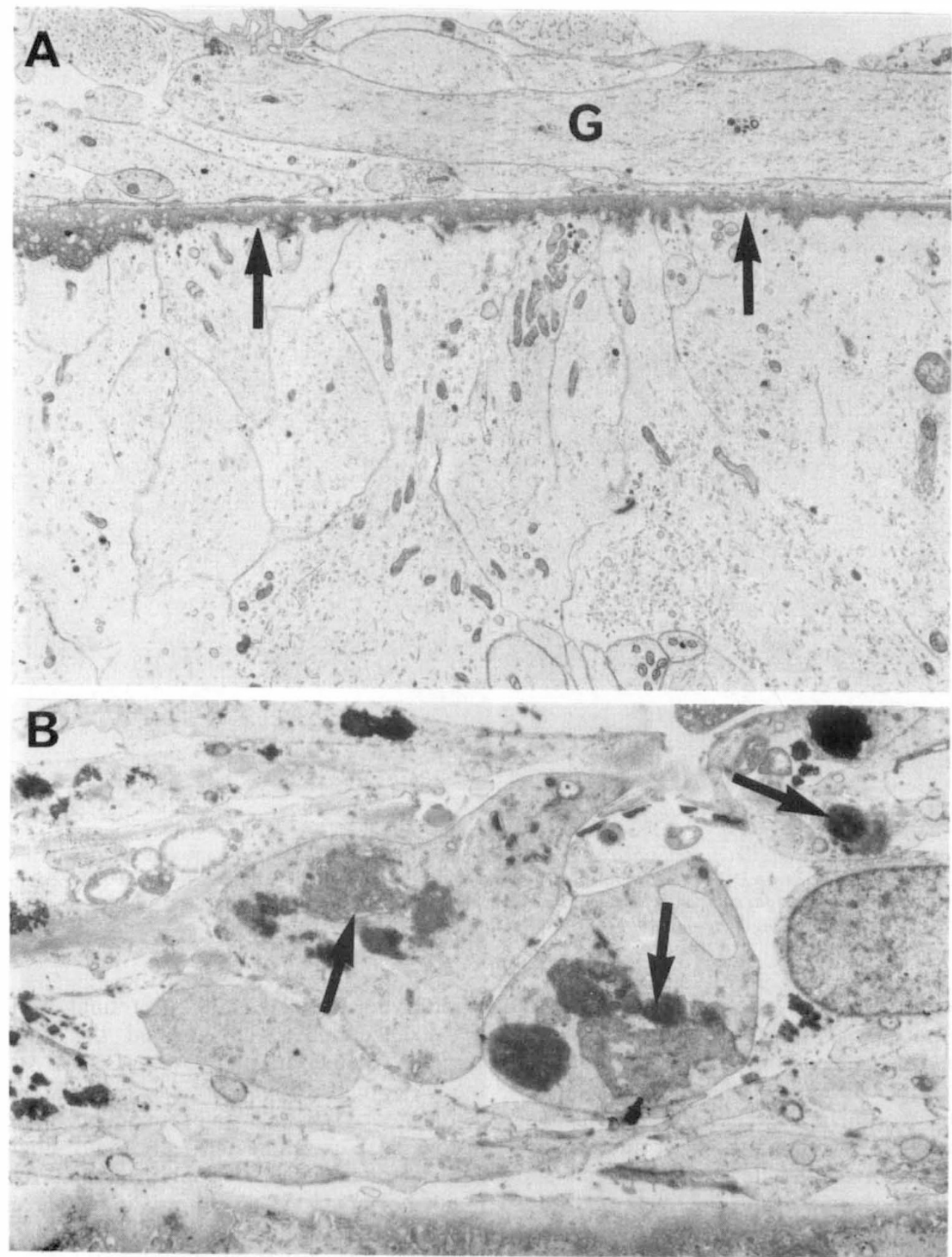

Fig. 3. Transmission electron micrographs of simple epiretinal membranes:

(a) glial cell process $(G)$ of an idiopathic epiretinal membrane, parts of which are only one-cell thick; inner limiting lamina is arrowed. $\times 5,000$

(b) glial cells in an epiretinal membrane secondary to retinal venous occlusion and vitreous haemorrhage; glial phagosomes (arrows) containing haematogenous breakdown products. $\times 6,300$. 

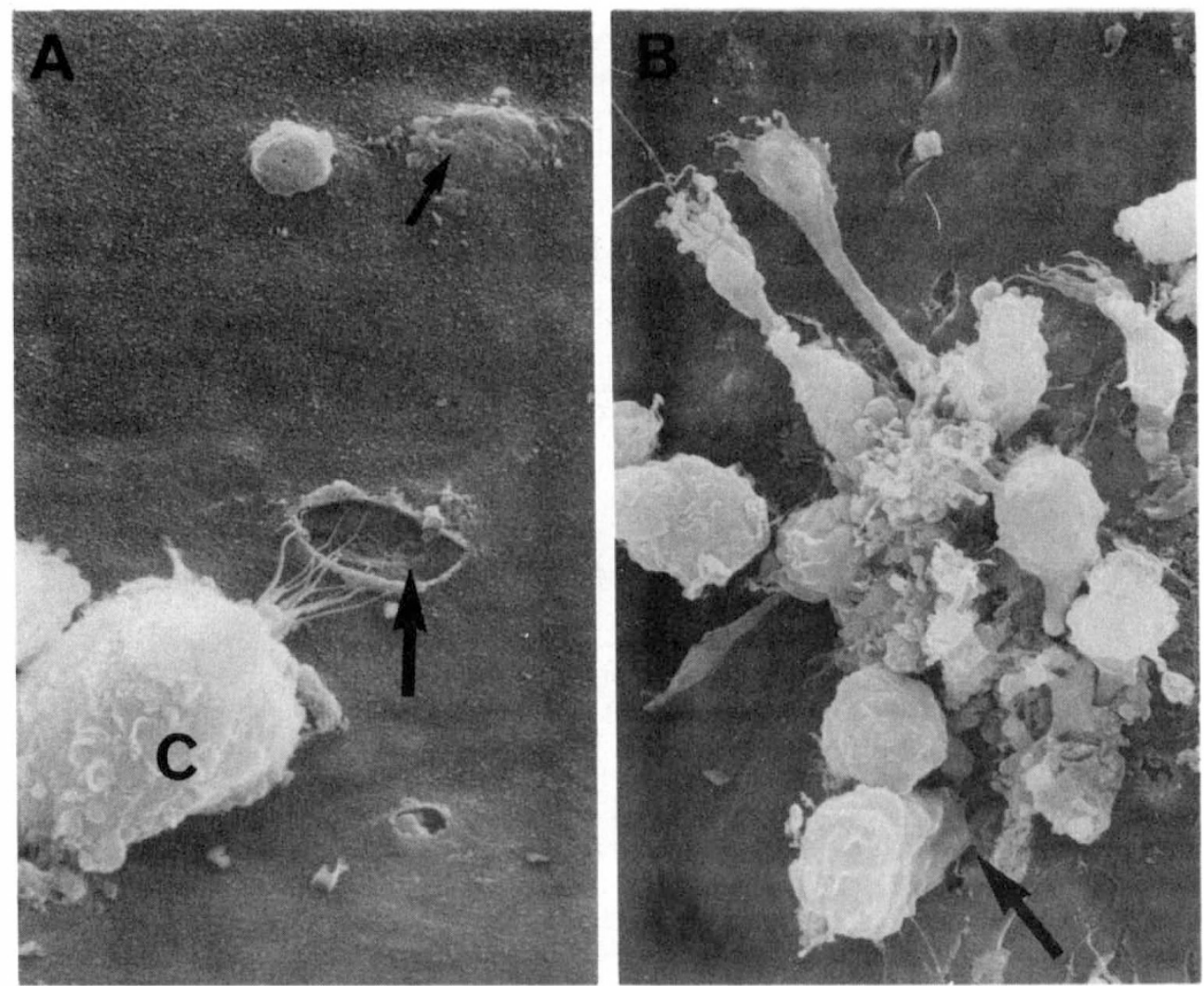

Fig. 4. Scanning electron micrographs of retinal surface of an eye with retinal venous occlusion and vitreous haemorrhage:

(a) ruffled rounded cell (C) adjacent to break (large arrow) in the inner limiting lamina which also shows a bulge (small arrow) possibly produced by protruberance of sublaminar Muller cells. $\times 2,000$

(b) cluster of epiretinal cells associated with a break in the inner limiting lamina (arrow); some cells are flattened and elongated while others are round and ruffled

face of the retina, invariably associated with a (transparent) ERM, are a frequent incidental finding in the posterior fundus during macroscopic examination of autopsy eyes. ${ }^{31,32}$ Associated surface breaks are present but often difficult to detect by light microscopy. The wrinkling characteristically affects the ILL and innermost part of the nerve-fibre layer with no involvement of the deeper retinal layers or disturbance of the retinal vessels. The ERMs in the central part of each SWR lesion comprise one or more layers of flattened glial cells forming a taut surface membrane adherent to the peaks of the retinal wrinkles. Since these were autopsy specimens, little clinicopathological correlation was possible. It is uncertain, for example, whether the associated autolytic retinal swelling exaggerated or diminished the macroscopic visualisation of the ERMs or, indeed, their apparent tractional consequences. However, since many of these lesions were extramacular, with no histological effects on the deeper retinal structures, it is likely that most were asymptomatic and correspond to SWR as defined clinically.

Clinico-ultrastructural correlation of an SWR lesion in a well-fixed enucleated globe reported by Bellhorn and colleagues ${ }^{29}$ revealed predominantly fibrous astrocytes (with abundant cytofilaments) together with Muller cells and other cells with electrondense cytoplasm. Thus, the ERMs of simple and SWR lesions (which frequently coexist) ${ }^{31}$ 

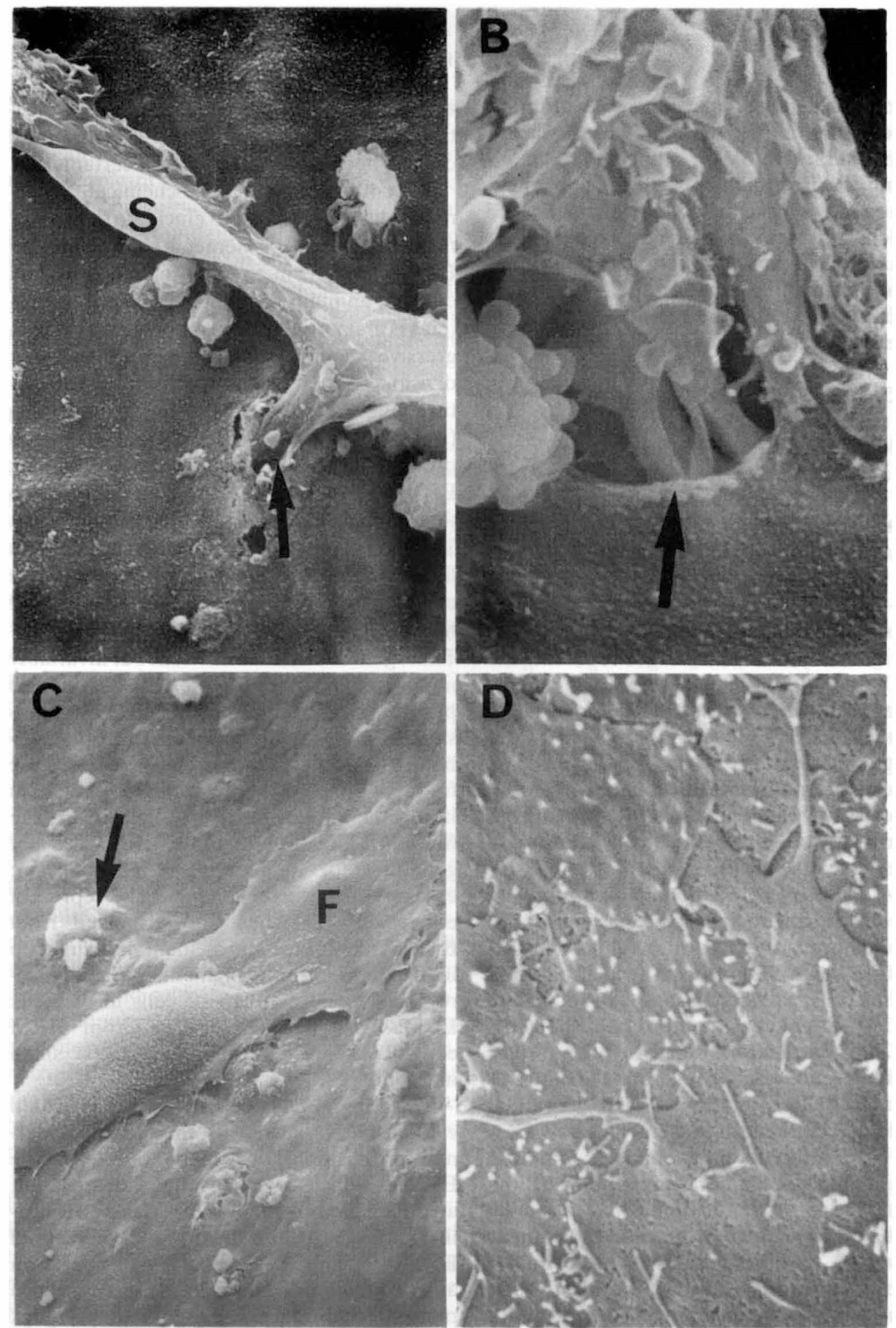

Fig. 5. Scanning electron micrographs of same specimen as (4):

(a) spindle-shaped cell $(S)$ on an extremely large elongated cell with a process which passes through a break (arrow) in the inner limiting lamina. $\times 1,700$

(b) break in the inner limiting lamina (arrow) through which a cell is extending. $\times 8,000$

(c) elongated flattened migratory cell with anterior fan $(F)$ adjacent to a bulge (arrow) in the inner limiting lamina produced by a Muller cell. $\times 800$

(d) flattened plate-like cells with prominent microvilli and overlapping boundaries forming a simple epiretinal membrane. $\times 7,000$ 
have a similar cellular basis. The different consequences appear to reflect contractility of the membrane in SWR; other factors determining the tractional consequences presumably include the capacity for the ILL and Mullers end-feet to 'slide' over the deeper retinal structures ${ }^{29}$ and the anchorage established between the ERM and ILL, ${ }^{29}$ between the ILL and Mullers end-feet ${ }^{24}$ and between epiretinal and sustentacular glia. ${ }^{12,27,28}$

\section{(c) Complex ERM:}

This term defines an ERM of more substantial proportions with a multiplicity of cell types and a capacity for collagen synthesis. Complex ERMs are associated with severe tractional effects in the underlying retina (i.e. FTRF lesions) including those seen in PVR. The tangential tractional forces are presumably transmitted through the whole thickness of the retina by the sustentacular glia. ${ }^{12,28}$ For over a century, debate has raged regarding the cellular derivation of complex ERMs, in particular the cells responsible for ERM contraction..$^{33,34,35}$

Light microscopic ${ }^{35.36}$ and, latterly, electron microscopic studies ${ }^{36-40}$ of enucleated globes and excised ERMs have mainly investigated secondary and iatrogenic membranes with few reports specifically concerning idiopathic ERMs with severe tractional consequences. ${ }^{9}$ Based on ultrastructural criteria, ${ }^{39}$ the principal feature differentiating complex ERMs from simple ERMs is the presence, in addition to glial cells, of fibroblast or fibroblast-like cells (which are considered to be responsible for ERM contraction), together with a greater preponderance of small macrophages and collagen. In PVR and iatrogenic ERMs, retinal pigments epithelial cells are also present ${ }^{36,38,39.40,43}$ ) while in uveitis inflammatory cells may be a major component of the ERM. ${ }^{41}$

Interest has chiefly centred on the cellular derivation of the fibroblasts-i.e. whether these are true mesodermal fibroblasts (e.g. from the retinal vascular adventitia), or have a neuroectodermal origin (i.e. from differentiation of glial or pigment epithelial cells). However, electron microscopy is of limited value in such investigations since the cells studied may not be representative of the whole ERM and there is increasing difficulty in identification of metaplastic cells since ultrastructural criteria become progressively uncertain.

Recently, immunohistochemical techniques have been used to elucidate the role of neuroectodermal elements in excised ERMs; ${ }^{27,41,42,43,48}$ in contrast to ultrastructural criteria, immuno-staining of cytoskeletal proteins is maintained or even increases with progressive dedifferentiation, metaplasia or division and migration in primary tissue culture (Fig. 6). Specific glial immuno-staining (using anti-GFAP antibdies) has revealed the presence of glial cells in virtually all complex ERMs. ${ }^{27}$ They tend to form a lamina similar to that seen in simple and SWR lesions ${ }^{27,42}$ (Fig. 7), but no evidence was found suggesting a fibroblastic transformation of glial cells in complex human ERMs (i.e. the associated fibrous component was GFAP-negative). Thus, glial cells are a consistent but invariably minor component of complex ERMs (up to 30 per cent of constituent cells only). Immunostaining of pigment epithelial cells using antibodies against cytokeratins has confirmed the frequent presence of epithelial cells in iatrogenic and PVR ERMs. ${ }^{43}$ However, the fibroblast-like cells in these ERMs are not generally of pigment epithelial origin; cytokeratin-positive cells merely represent either cells detached and dispersed from Bruch's membrane and incidentally caught up in the ERM, or large pigment epithelial macrophages. The majority of cells in complex ERMs, or growing in vitro from ERM explants, are fibroblasts and small macrophages. ${ }^{27,43,48}$

Thus, immunohistochemistry has provided evidence at variance with the 'neuroectodermal proposition' of genesis of contractile ERMs $^{3}$ which, when fully extrapolated, attributes non-pigmented ERMs to glial proliferation and contraction, and pigmented ERMs to pigment epithelial cell proliferation and contraction. Glial cells are present in both pigmented and non-pigmented complex ERMs but do not appear to be responsible for ERM contraction in either. ${ }^{27}$ Furthermore, while biomicroscopic pigmentation of an ERM generally suggests a pigment epithelial component, it is no guide to the cellular deri- 
vation of the contractile component of the ERM. ${ }^{43}$

Finally, it has been suggested that biomicroscopic opacification of an ERM has a clear-cut clinico-pathological correlate in the presence of abundant collagen..$^{40} \mathrm{We}$ were unable to confirm this in our recent quantitative clinico-histopathological study ${ }^{41}$ which showed that predominantly cellular ERMs may be just as biomicroscopically opaque as collagenous scars.

\section{Vitreous Interrelationships}

Simple ERMs have been reported in eyes both with and without established PVD. The presence of cortical vitreous fibrils between the ERM and the ILL in some instances may attest to the possibility that PVD occurred subsequent to the proliferation of the ERM, with splitting of cortical gel on the vitreal side of the membrane. ${ }^{44}$ In SWR lesions in autopsy eyes, macroscopic identification of PVD by the hanging-drop method revealed PVD in 80 per cent of affected eyes, either complete or partial (in the region of the ERM). ${ }^{31,32}$ Most complex ERMs studied pathologically develop in the context of complete PVD.

The absence of PVD in 20 per cent of autopsy 'eyes with SWR lesions correlates interestingly with that in clinical idiopathic FTRF lesions. ${ }^{23}$ The main difference is the virtual absence of localised vitreomembranous adhesions in the autopsy SWR series; ${ }^{32}$ this may reflect the difference in aetiology and severity of the lesions, disruption of tenuous vitreomembranous adhesions by autopsy specimen preparation, or alternatively an exaggerated preponderance of clinical vitreomembranous adhesions because of the higher likelihood of symptomatic presentation.

\section{Age-Relationship}

Because of the impracticality of the good tissue fixation and serial retinal sectioning required to reveal macroscopically-invisible lesions, there is no substantial data on the agerelationships of simple ERMs other than to note their potential occurrence even in young individuals ${ }^{24}$ and the impression of at least 50 per cent occurrence in eyes over 50 years old by Foos. ${ }^{45}$ However, studies of SWR lesions identified macroscopically in large numbers of autopsy eyes (albeit including not only idiopathic ERMs, but also ERMs in aphakic eyes and ERMs associated with retinal infarcts and diabetic retinopathy) demonstrate a clear-cut relationship of SWR to increasing age; 31,3225 per cent of eyes of patients over 78 years contained such lesions. This contrasts with the lack of age-relationship for peripheral vitreoretinal lesions like lattice degeneration, ${ }^{46}$ although age-related $\mathrm{PVD}^{47}$ and a tendency to retinal break formation in relation to lattice and other lesions underscores the potential for iatrogenic and PVR proliferations with increasing age.

\section{Course}

Pathological studies of autopsied and enucleated eyes do not, of course, readily lend themselves to longitudinal study of ERM-progression. Nevertheless, scanning electron microscopy of a single specimen can give a vivid impression of the formation of a glial epiretinal membrane following outgrowth through multiple breaks in the ILL (Figs. 4, 5). The change from the intense 'activity' in the perikaryon of early glial outgrowths to the more subdued and stable perikaryon of established monolayers or multicellular laminae in simple ERMs and SWR is also of interest. ${ }^{24}$ Once the ERM is fully established, it would appear that the glia remain viable indefinitely, and this remains true of the glial lamina of long-standing complex fibroglial ERMs removed by closed microsurgery. ${ }^{41}$ This contrasts with the fibrous component of excised complex ERMs as demonstrated in our studies comparing 'early' ERMs (i.e. those removed within four months of the time of estimated onset) with 'late' ERMs (i.e. those removed more than four months from the time of estimated onset). Notwithstanding the inherent problems of such an investigation, examination of large numbers of ERMs revealed a statistically-significant difference between early and late ERMs in respect of cellularity $^{41}$ (early ERMs containing more cells per unit of tissue than late ERMs), collagen content ${ }^{41}$ (late ERMs containing more collagen than early ERMs), and growth potential in tissue culture ${ }^{48,49}$ (early ERMs establishing outgrowths more consistently, 
more rapidly and more extensively than late ERMs). Although our ERMs were mainly in the secondary or iatrogenic/PVR aetiological categories, this time-dependent change from a contractile cellular membrane to a consolidated collagenous scar containing few viable cells probably holds true for idiopathic ERMs. Failure to appreciate the differences in time-dependent change between the glial and non-glial components of complex ERMs can result in misapprehension of the role of glia, particularly in late ERMs.

\section{Pathogenic Sequence and Experimental Studies}

From ultrastructural studies ${ }^{39}$ endorsed by immunohistochemistry, ${ }^{27}$ the concept has emerged of the 'fibroglial ERM' as the basis of age-related contractile events on the surface of the posterior retina. What is the pathogenesis of this process? Why do glial cells escape from the confines of the retina and what is their role in this new location? What stimulates the development of a fibrous contractile component in the ERM and whence are the responsible cells derived?

\section{Glial Component}

Outgrowth of glia through retinal surface breaks has been widely regarded as a 'reparative' process following an initial 'traumatic' or 'biomechanical' event such as PVD which ruptures the ILL. The main argument in favour of this pathogenic sequence is the exaggerated (approximately 2-fold) age-corrected incidence of PVD in eyes with ERMs. ${ }^{10}$ Corroborating evidence is, however, extremely scanty; a significant proportion of ERMs are known to grow within attached cortical gel, there are very few reports of ILL avulsion with PVD, ${ }^{12}$ and clinically detectable lesions were extremely rare during follow-up of cases with symptomatic PVD. ${ }^{50,51}$ Furthermore, spontaneous or surgical peeling of ERMs is frequently associated with ILL stripping ${ }^{12.36}$ but subsequent repair processes are unusual. Foos has also pointed out that, since rhegmatogenous PVD is initiated in the posterior pole, contractile events within ERMs in attenuated posterior cortical vitreous may precipitate PVD. ${ }^{44}$

Although 'glial repair' is a feature of experi- mental retinal lacerations, ${ }^{52,53}$ animal models have recently corroborated the alternative mechanism of glial outgrowth through the ILL-i.e. disruption of the ILL by the glial cells themselves (Figs. 4, 5, 8). Good evidence for this mechanism has emerged from our rabbit model of uveitis and ERM formation in response to intravitreal injection of Shigella endotoxin. ${ }^{54}$ From five weeks following injection, Muller cells formed multiple focal protuberances up to $30 \mu$ in diameter beneath the ILL, and then erupted through a previously intact ILL to establish an epiretinal outgrowth and subsequent GFAP-positive ERM. Preexisting holes in the ILL from associated PVD or macrophage migration were excluded, and the Muller cells incorporated ${ }^{3} \mathrm{H}$-thymidine at the time of outgrowth. Similar outgrowths of glia through intact ILL were revealed in a study of the Algevere-Kock fibroblast-injection model of ERM formation in rabbits, an event contemporary with establishment of fibroblastic vitreous membrąnes and possibly a consequence of inflammation induced by dead fibroblasts, ${ }^{55}$ and also following laceration $^{53}$ or photocoagulation ${ }^{56}$ of rabbit retina. Muller cell outgrowths, probably without antecedent ILL rupture, have also been noted following intravitreal injection of carbon particles ${ }^{57}$ and red blood cells $;{ }^{58}$ phagocytosis may be one of the 'purposes' of the glial outgrowth. Such experiments suggest that glial ERM formation is typically a response to a chronic stimulus, often inflammatory, rather than an acute biomechanical event such as PVD. A similar conclusion was drawn from our organ-culture autoradiographic investigation of excised complex ERMs-'anarchistic scars' ${ }^{41}$ - and accords with the clinical association of ERMs with retinal ischaemia and inflammation. Thus, idiopathic age-related ERM formation is unlikely to be attributable simply to PVD; as Wise put it-'the disease is retinal in origin, and the vitreous changes are secondary and relatively inconsequential' ${ }^{6}$

\section{Fibrous Component}

Excepting minor contractile lesions in man (e.g. SWR, wherein only glial cells have so far been implicated), the contractile component of ERMs appears to be non-glial (as well as generally non-epithelial) in origin. The two 


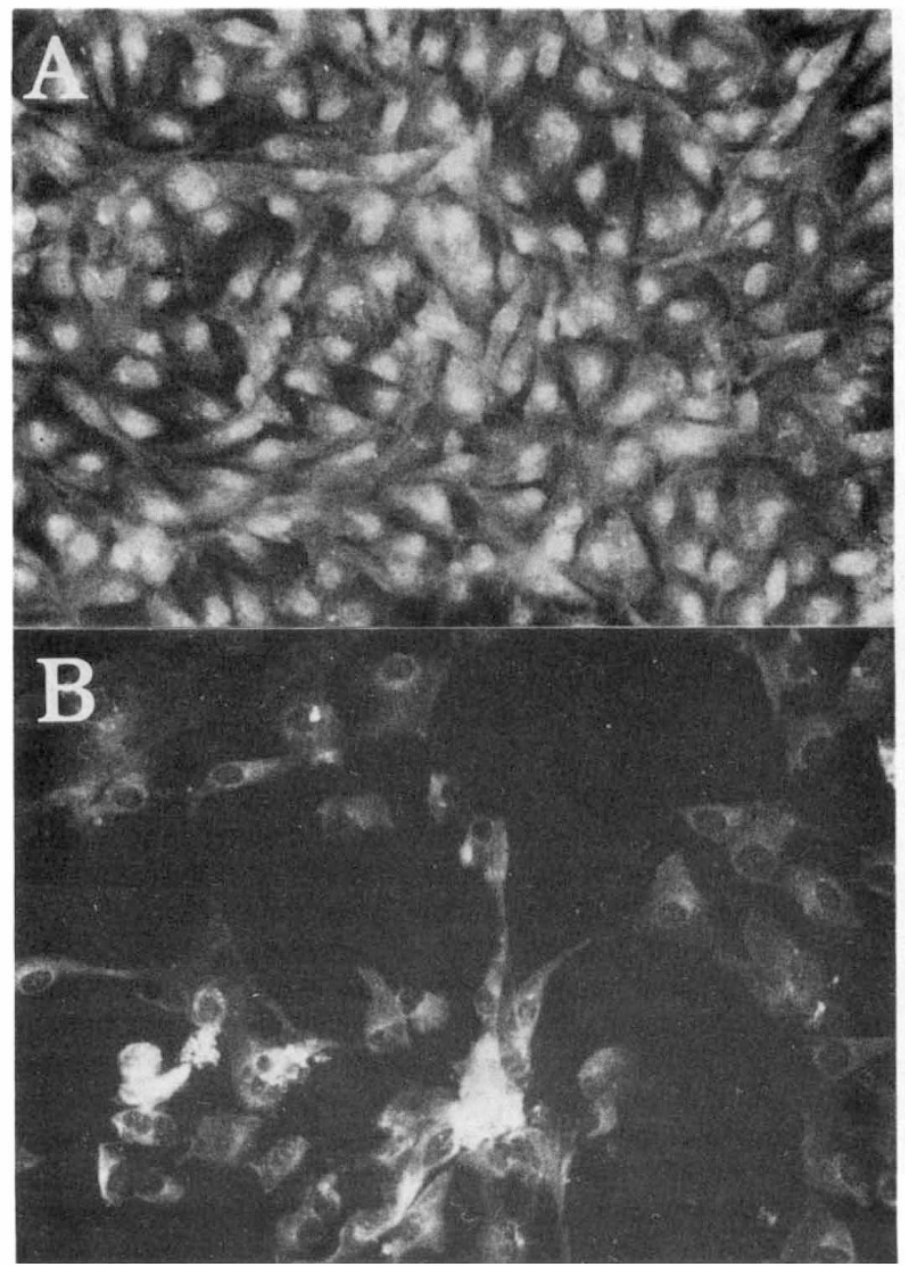

Fig. 6. Immunohistochemical fluorescent staining of cells in tissue culture:

(a) monolayer of bovine retinal pigment epithelial cells showing prominent anti-prekeratin staining

(b) cells from an excised epiretinal membrane explant showing occasional prekeratin-positive cells among a majority of prekeratin-negative fibroblasts.

most likely sources of the epiretinal fibroblasts are hyalocytes ${ }^{9,39,59}$ or retinal perivascular fibroblasts. ${ }^{33}$ Unfortunately, there is as yet no immunohistochemical method of distinguishing these cell-origins, though we favour a prominent role of retinal adventitial fibroblasts in fibroglial ERMs for a number of reasons. Firstly, the topographical relationship of surface retinal breaks to retinal vessels identified in respect of glial ERMs also provides ready access for migrating fibroblasts to the retinal surface. Secondly, a minor vascular component is found in a significant proportion (in 23 per cent of our series) of excised ERMs studied histopathologically, ${ }^{54}$ notwithstanding their clinical 'non-vascular' status. This holds true not only for ERMs secondary to inflammatory disease, where clinical ERM vascularisation is sometimes a prominent feature, but also occasionally in idiopathic age-related ERMs. Thirdly, vascularised membranes, i.e. 'fibrovascular' ERMs (as distinct from 'fibrocellular' ERMs) proliferating in eyes with extensive areas of retinal capillary 


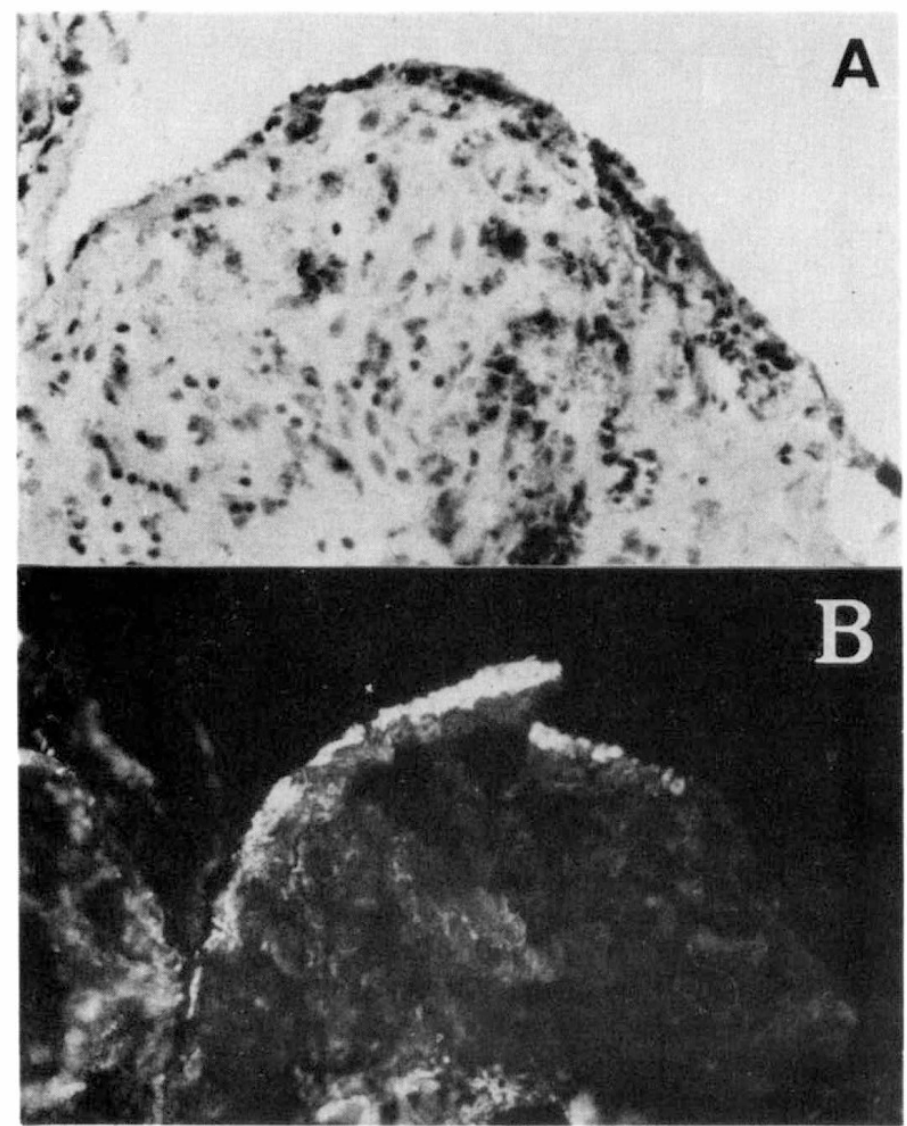

Fig. 7. Light microscopic sections from an excised epiretinal membrane: (a) conventional staining

(b) anti-GFAP immunostaining shows a glial lamina bordering GFAPnegative cells constituting the bulk of the ERM specimen.

non-perfusion, produce clinically-identical contractile consequences and, apart from their prominent vascular component, have similar glial and non-glial (GFAP-negative) fibrous elements to those in non-vascularised ERMs (though collagen production tends to be much more exuberant in vascularised ERMs). In some cases of proliferative diabetic retinopathy, extensive fibroglial ERMs may occur with only a minor neovascular component initially. Moreover, vascularised and non-vascularised ERMs often coexist, for example in diabetics and following retinal vein occlusion. Fourthly, supportive evidence derives from our rabbit ERM model following intravitreal injection of Shigella endotoxin. ${ }^{54}$ In addition to a GFAP-positive ERM pro- liferating over attached undistorted peripheral retina, a fibroglial ERM grew in the posterior pole in the region of the optic disc and medullary ray beneath which the retina was distorted or detached. This membrane contained GFAP-negative fibroblasts in addition to glial cells which were continuous with retinal glia through multiple defects in the ILL. The fibroblastic cells (which were also non-epithelial and non-endothelial by immunohistochemistry) showed avid ${ }^{3} \mathrm{H}$-thymidine uptake and appeared to derive from the adventitia of the (albeit extraretinal) blood vessels in the vascular complex of the medullary ray.

Since contractile ERMs share many of the characteristics of healing wounds, much inter- 

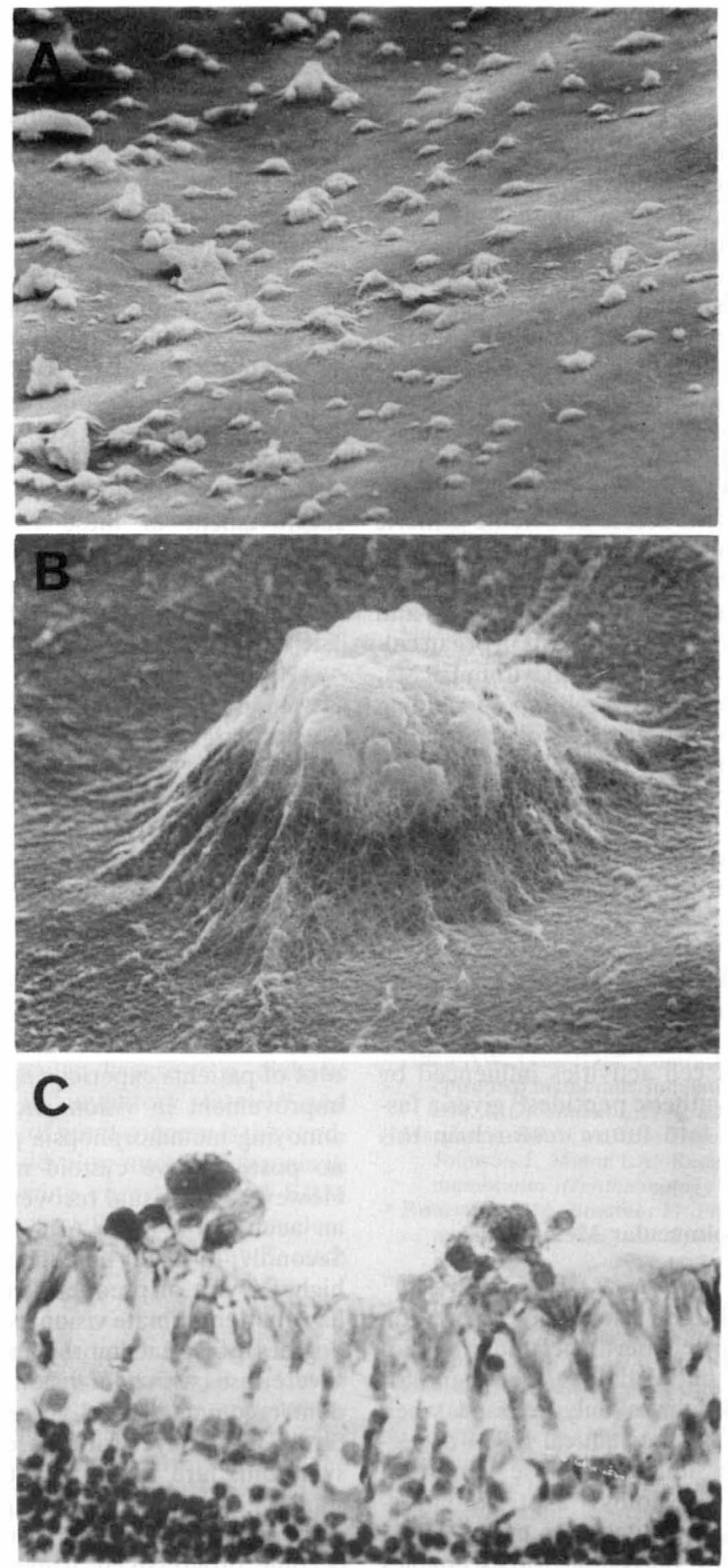

Fig. 8. Rabbit models of glial outgrowth:

(a) scanning electron micrograph of surface of retina one week after intravitreal injection of skin fibroblasts; multiple surface bulges produced by Muller cells. $\times 300$

(b) higher power of one of the bulges in (a); cellular elements erupting through inner limiting lamina onto retinal surface. $\times 3,500$

(c) light micrograph stained for GFAP 5 weeks following intravitreal injection of Shigella endotoxin; GFAPpositive Muller cells within the retina and two clusters of epiretinal glia. 
est has recently centered on biochemical compounds known to be involved in woundhealing such as fibronectin, platelet-derived growth factor and interleukin. The glycoprotein fibronectin has multiple roles in wound healing-chemoattractant, adhesive and opsonic-and is present in substantial quantities in the vitreous of eyes with PVR (but to a lesser extent in eyes with localised iatrogenic ERMs) in contrast to the low levels in the vitreous of eyes with retinal detachment unaccompanied by ERM proliferation. ${ }^{60}$ This may be a reflection of breakdown of the blood retinal barrier and access of soluble dimeric FN to the vitreous cavity. Fibronectin is also a prominent component of human complex ERMs - 'contractile cohesive units'41_ and autoradiography of exised ERMs in organ culture suggests in situ production within ERMs, probably from most ERM cell-types including glial cells, pigment epithelial cells and fibroblasts. Experimentally, fibronectin has been demonstrated in endotoxin-induced fibroglial ERMs,${ }^{54}$ and intravitreal injection of fibronectin and platelet-derived growth factor can induce ERM formation and TRD in association with penetrating injury. ${ }^{61}$ Fibronectin and other growth factors are undoubtedly of fundamental importance in determining the onset, course and severity of ERMs in the various clinical settings; pharmacological manipulation of cell activities influenced by fibronectin by synthetic peptides ${ }^{62}$ gives a fascinating insight into future research in this area.

\section{Treatment of Epimacular Membranes}

\section{Techniques}

Wise attempted argon laser photocoagulation of cystoid retinal oedema associated with idiopathic ERMs ${ }^{6}$ but definitive treatment for epimacular ERMs was only realised when Machemer applied mechanical ERM dissection techniques similar to those employed during diabetic vitrectomy. ${ }^{63}$ Posterior vitrectomy followed by engagement of the ERM and peeling using tangential forces enables the membrane (and often a large area of ILL $^{12,36}$ ) to be removed from the retinal surface with a variable (and unpredictable) amount of difficulty. Well-established thick collagenous ERMs are generally easier to dissect than early proliferations or thin transparent ERMs (though care must be taken to remove all lamellae). Alternatively, viscodelamination of the ERM using Healon has been recommended by Stenkula. ${ }^{64}$ Most recently, non-invasive laser treatment was reported for idiopathic epimacular ERMs associated with partial PVD in three eyes. ${ }^{65}$ Although direct photodisruption of an ERM is currently impossible without associated retinal damage, YAG laser treatment of cortical gel in the region of the ERM resulted in visual improvement in these cases, presumably either by reducing vitreomacular traction or by inducing ERM peeling with further PVD. This technique might possibly be of value for ERMs with no associated PVD.

\section{Results of Epimacular Membrane Peeling}

Several large surgical series have been published ${ }^{11,13,15,19,66}$ and, while earlier reports mainly concerned the treatment of secondary and iatrogenic ERMs, surgery for idiopathic ERMs has latterly figured prominently (including 134 elderly patients with severe idiopathic lesions). ${ }^{15}$ The conclusions to be drawn from these series are sometimes conflicting, but a number of generally-agreed principles have emerged. Firstly, the operation is very effective, approximately 80 per cent of patients experiencing at least a 2-line improvement in vision and a reduction in annoying metamorphopsia provided there is no postoperative cystoid macular oedema. However, full visual recovery is uncommon, an acuity of $6 / 12$ to $6 / 18$ being the norm. Secondly, as might be anticipated, eyes with higher levels of preoperative vision tend to have better ultimate vision, while the greatest degrees of visual improvement are seen in severe cases with poor vision. ${ }^{19}$ Surgery is seldom recommended if vision is better than $6 / 18$. Thirdly, eyes with more recent onset of symptoms fare better than those with longstanding visual loss, implying that the visual consequences of tangential macular traction become progressively irreversible as is also the case in rhegmatogenous macular retinal detachment.

The presence of preoperative cystoid macular oedema or fluorescein leakage has been 
variously reported as being an adverse prognostic factor ${ }^{13,19}$ or of no significance..$^{15}$ Similarly, thick or opaque ERMs have been reported as both good ${ }^{19.67}$ and bad ${ }^{13.15}$ prognostic indicators compared with thin transparent ERMs. Furthermore, surgery for idiopathic ERMs has been reported as more visually beneficial than that for secondary or iatrogenic $\mathrm{ERMs}^{15}$ while other reports suggest little difference in outlook according to aetiology or even a better prognosis for some iatrogenic ERMs. ${ }^{19}$ Differences in case selection, aetiological groupings, statistical methods and functional criteria probably underlie these conflicting results.

Age does not appear to be a major factor in predicting surgical outcome. Michels ${ }^{68}$ suggested that older patients have less visual recovery than younger patients, and this certainly appears to be true of iatrogenic ERMs. ${ }^{19}$ Surprisingly, older patients with idiopathic ERMs fared better than younger patients in the series of Rice and colleagues $;^{19}$ our experience has been that full visual recovery has only occurred in young patients with idiopathic ERMs. ${ }^{12.41}$

Intraoperative complications of membrane-peeling (e.g. retinal breaks) are infrequęnt and can be readily dealt with. Recurrent ERMs are unusual except, significantly, after surgery for membranes secondary to retinal vascular disease (e.g. diabetic retinopathy), ${ }^{15.69}$ inflammatory states ${ }^{15.41}$ and trauma ${ }^{15}$ Finally, of great concern is the tendency for eyes to develop nuclear sclerosis in the months following vitrectomy and ERM peeling $;{ }^{11,15.19}$ it may well be that, like nuclear sclerosis after diabetic vitrectomy, ${ }^{70}$ such changes are age-related.

We thank Miss Heather Lucas for preparing the manuscript and Messrs. K. Sehmi and R. C. Howes for the illustrations. We gratefully acknowledge the support of the Wellcome Trust (grant no. 10998/ 1.5), the TFC Frost Charitable Trust, the Help the Hospitals Fund, the Muirhead Settlement and the British National Committee for the Prevention of Blindness.

\footnotetext{
References

${ }^{1}$ Foos RY: Nonvascular proliferative extraretinopathies. Am. J. Ophthalmol. 1978; 87: 723-5.

${ }^{2}$ Foos RY: The spectrum of nonvascular proliferative
}

extraretinopathies. Chapter 6 in Ocular Pathology Update. Ed. D H Nicholson. Messon Publ. Co., New York, 1980.

${ }^{3}$ Laqua H, Machemer R: Clinico-pathological correlation in massive periretinal proliferation. $A m$. J. Ophthalmol. 1975; 80: 913-29.

${ }^{4}$ The Retina Society Terminology Commitee: The classification of retinal detachment with proliferative vitreoretinopathy. Ophthalmology 1983; 90: 121-5.

${ }^{5}$ Gass JDM: Macular dysfunction caused by vitreous abnormalities. Chapter 11 (pp 200-215) in Stereoscopic Atlas of Macular Diseases. C V Mosby Co., St. Louis, 1970.

${ }^{6}$ Wise GN: Clinical features of idiopathic preretinal macular fibrosis. Am. J. Ophthalmol. 1975; 79: 349-57.

7 Jaffe NS: Macular retinopathy after separation of vitreoretinal adherence. Arch. Ophthalmol. 1967; 78: 585-91.

${ }^{8}$ Maumenee AE: Further advances in the study of the macula. Arch. Ophthalmol. 1967; 78: 151-65.

${ }^{9}$ Kampik A, Green WR, Michels RG: Ultrastructural features of progressive idiopathic epiretinal membrane removed by vitreous surgery. Am. J. Ophthalmol. 1980; 90: 797-809.

${ }^{10}$ Sidd RJ, Fine SL, Owens SL, Patz A: Idiopathic preretinal gliosis. Am. J. Ophthalmol. 1982; 94: 44-8.

${ }^{11}$ Michels RG: Vitreous surgery for macular pucker. Am. J. Opthalmol. 1981; 92: 628-39.

12 McLeod D, Marshall J, Grierson I: Epimacular membrane peeling. Trans. Ophthalmol. Soc. UK. 1981; 101: 170-80.

13 Trese MT, Chandler DB, Machemer R: Macular pucker I: Prognostic criteria. Graefe Arch. fur Ophthalmol. 1983; 221: 12-15.

${ }^{14}$ Allen AW, Gass JDM: Contraction of a perifoveal epiretinal membrane simulating a macular hole. Am. J. Ophthalmol. 1976; 82: 684-91.

${ }^{15}$ Margherio RR, Cox MS, Trese MT, Murphy PL, Johnson J, Minor LA: Removal of epimacular membranes. Ophthalmology 1985; 92: 1075-82.

${ }^{16}$ Robertson DM, Buettner H: Pigmented preretinal membranes. Am. J. Ophthalmol. 1977; 83: 824-9.

${ }^{17}$ Baines PS, Hiscott PS, McLeod D: Posterior nonvascularised proliferative extraretinopathy and peripheral nodular retinal telangiectasis. Trans. Ophthalmol. Soc. UK. 1982; 102: 487-91.

${ }_{18}$ Hansen RI, Friedman AH, Gartner S, Henkind P: The association of retinitis pigmentosa with preretinal macular gliosis. Br. J. Ophthalmol. 1977; 61: $597-600$.

${ }^{19}$ Rice TA, de Bustros S, Michels RG, Thompson JT, Debanne SM, Rowland DY: Prognostic factors in vitrectomy for epiretinal membranes of the macula. Ophthalmology 1986; 93: 602-10.

${ }^{20}$ Tanenbaum HL, Schepens CL, Elzeneiny I, Freeman HM: Macular pucker following retinal detachment surgery. Arch. Ophthalmol. 1970; 83: 286-93.

${ }^{21}$ Hagler WS, Aturaliya U: Macular puckers after reti- 
nal detachment surgery. Br. J. Ophthalmol. 1971; 55: 451-7.

${ }^{22}$ Lobes LA, Burton TC: The incidence of macular pucker after retinal detachment surgery. Am. J. Ophthalmol. 1978; 85: 72-7.

${ }^{23}$ Hirokawa H, Jalkh AE, Takahashi M, Takahashi M, Trempe CL; Schepens CL: Role of vitreous in idiopathic preretinal macular fibrosis. Am. J. Ophthalmol. 1986; 101: 166-9.

${ }^{24}$ Foos RY: Vitreoretinal juncture-simple epiretinal membranes. Graefes Arch. fur Ophthalmol. 1974; 189: 231-50.

${ }^{25}$ Wolter JR: Glia of the human retina. Am. J. Ophthalmol. 1959; 48: 370-92.

${ }^{26}$ Daicker B, Guggenheim R, Gywat L: Findings on retinal surface by scanning electron microscopy III. Epivascular glial clusters. Graefes Arch. fur Ophthalmol. 1977; 204: 31-7.

${ }^{27}$ Hiscott PS, Grierson I, Trombetta CJ, Rahi AHS, Marshall J, McLeod D: Retinal and epiretinal glia-an immunohistochemical study. Br. J. Ophthalmol. 1984; 68: 698-707.

${ }^{28}$ Foos RY: Vitreoretinal juncture over retinal vessels. Graefes Arch. fur Ophthalmol. 1977; 204: 22334.

${ }^{29}$ Bellhorn MB, Friedman AH, Wise G, Henkind P: Ultrastructure and clinicopathologic correlation of idiopathic preretinal macular fibrosis. Am. J. Ophthalmol. 1975; 79: 366-73.

${ }^{30}$ Szamier RB: Ultrastructure of the preretinal membrane in retinitis pigmentosa. Invest. Ophthalmol. 1981; 21: 227-36.

${ }^{31}$ Roth AM, Foos RY: Surface wrinkling retinopathy in eyes enucleated at autopsy. Trans. Am. Acad. Ophthalmol. Otolaryngol. 1971; 75: 1047-58.

${ }^{32}$ Foos RY: Surface wrinkling retinopathy. Chapter 3 (pp 23-38) in Vitreous Surgery and Advances in Fundus Diagnosis and Treatment. Ed. Freeman, Hirose and Schepens. Appleton-Century-Crofts. New York, 1977.

${ }^{33}$ Parsons JH: The Pathology of the Eye, Volume 2. Publ. Hodder and Stoughton, London 1905.

${ }^{34}$ Smith TR: Pathological findings after retina surgery. In: Importance of the Vitreous Body in Retina Surgery with Special Emphasis on Reoperations. Ed. Schepens CL. Publ. C V Mosby Co., St. Louis, 1960 (pp 61-75).

${ }^{35}$ Clarkson JG, Green WR, Massof D: A histopathological review of 168 cases of preretinal membrane. Am. J. Ophthalmol. 1977; 84: 1-17.

${ }^{36}$ Green WR, Kenyon KR, Michels RG, Gilbert HD, de la Cruz Z: Ultrastructure of epiretinal membranes causing macular pucker after retinal re-attachment surgery. Trans. Ophthalmol. Soc. UK. 1979; 99: 63-77.

${ }^{37}$ Rentsch FJ: The ultrastructure of preretinal macular fibrosis. Graeafes Arch. fur Ophthalmol. 1977; 203: 321-37.

${ }^{38}$ Newsome DA, Rodrigues MM, Machemer R: Human massive periretinal proliferation: in vitro characteristics of cellular components. Arch. Ophthalmol. 1981; 99: 873-80.

${ }^{39}$ Kampik A, Kenyon KR, Michels RG, Green WR, de la Cruz Z: Epiretinal and vitreous membranes: comparative study of 56 cases. Arch. Ophthalmol. 1981; 99: 1445-54.

${ }^{40}$ Trese M, Chandler DB, Machemer R: Macular pucker II: Ultrastructure. Graefes Arch. fur Ophthalmol. 1983; 221: 16-26.

${ }^{41}$ Hiscott PS, Grierson I, McLeod D: Natural history of fibrocellular epiretinal membranes: a quantitative, autoradiographic and immunohistochemical study. Br. J. Ophthalmol. 1985; 69: 810-23.

${ }^{42}$ Rodrigues MM, Newsome DA, Machemer R: Further characterisation of epiretinal membranes in human massive periretinal proliferation. Current Eye Research 1981; 1: 311-5.

${ }^{43}$ Hiscott PS, Grierson I, McLeod D: Retinal pigment epithelial cells in epiretinal membranes: an immunohistochemical study. Br.J. Ophthalmol. 1984; 68: 708-15.

${ }^{44}$ Foos RY: Vitreoretinal juncture; epiretinal membranes and vitreous. Invest. Ophthalmol. Visual Sci. 1977; 16: 416-22.

${ }^{45}$ Foos RY: Personal communication 1986.

${ }^{46}$ Foos RY, Simons KB: Vitreous in lattice degeneration of retina. Ophthalmology 1984; 91: 452-7.

${ }^{47}$ Foos RY, Wheeler NC: Vitreoretinal juncture: synchisis senilis and posterior vitreous detachment. Ophthalmology 1982; 89: 1502-12.

${ }^{48}$ Hiscott PS, Grierson I, Hitchins CA, Rahi AHS, McLeod D: Epiretinal membranes in vitro. Trans. Ophthalmol. Soc. UK. 1983; 103: 89-102.

${ }^{49}$ Jiang DY, Hiscott PS, Grierson I, McLeod D (1986): Growth and contractility of cells from epiretinal membranes in primary culture $\mathrm{Br}$. J. Ophthalmol (In Press).

50 Jaffe NS: Complications of acute posterior vitreous detachment. Arch. Ophthalmol. 1968; 79: 56871.

51 Wise GN: Relationship of idiopathic preretinal macular fibrosis to posterior vitreous detachment. Am. J. Ophthalmol. 1975; 79: 358-62.

52 Rentsch FJ: Preretinal proliferation of glial cells after mechanical injury of the rabbit retina. Graefes Arch. fur Ophthalmol. 1973; 188: 79-90.

${ }^{53}$ Miller B, Miller H, Patterson R, Ryan SJ: Retinal wound healing: cellular activity at the vitreoretinal interface. Arch. Ophthalmol. 1986; 104: $281-5$

${ }^{54}$ Hiscott PS: Epiretinal membranes: a pathological, clinical and experimental study. PhD Thesis, University of London, 1986.

${ }^{55}$ Hitchins CA, Grierson I, Hiscott PS: The effects of injections of cultured fibroblasts into the rabbit vitreous. Graefes Arch. fur Ophthalmol. 1985; 223: 237-49.

${ }^{56}$ Ohsawa E, Miki T: Scanning electron microscopic observation of glial cells following xenon arc photocoagulation. Graefes Arch. fur Ophthalmol. 1982; 218: 64-9.

${ }^{57}$ Algevere P, Kock E: Experimental epiretinal membranes induced by intravitreal carbon particles. Am. J. Ophthalmol. 1983; 96: 345-53.

${ }^{58}$ Miller B, Miller H, Ryan SJ: Experimental epireti- 
nal proliferation induced by intravitreal red blood cells. Am. J. Ophthalmol. (In Press).

${ }^{59}$ Gloor BP: Mitotic activity in the cortical vitreous cells (hyalocytes) after photocoagulation. Invest. Ophthalmol. 1969; 8: 633-46.

6) Campochiaro PA, Glaser BM: Pathogenesis of proliferative vitreoretinopathy. 5th Vail Vitreoretinal Seminar, March 1986.

${ }^{61}$ Yeo JH, Sadeghi J, Campochiaro PA, Glaser BM: Intravitreous fibronectin and platelet-derived growth factor: new model for traction retinal detachment. Arch. Ophthalmol. 1986; 104: 41721.

62 Avery RL, Glaser BM: Inhibition of retinal pigment epithelial cell attachment by a synthetic peptide derived from the cell-binding domain of fibronectin. Arch. Ophthalmol. 1986; 104: 1220-2.

${ }^{63}$ Machemer R: Die chirurgische Entfernung von epiretinalen Makulamembranen (Macular pucker). Klin. Monatsbl. Augenheilkd. 1978; 173: 36-42.

${ }^{64}$ Stenkula S, Ivert L: Sodium hyaluoronate (Healon) as an intravitreal aid in retinal and vitreous surgery. J. Ocul. Ther. Surg. 1984; 109-14.

${ }^{65}$ Brihaye-Van Geertruyden M, Tassignon MJ: Traitement du syndrome de Jaffe par le $Q$ switched Nd: Yag laser. Presentation to XV Meeting of Club Jules Gonin, August 1986.

${ }^{66}$ Michels RG: Vitrectomy for macular pucker. Ophthalmology 1984; 91: 1384-8.

${ }^{67}$ Michels RG: Surgery of epiretinal membranes. Dev. Ophthalmol. 1981; 2: 175-84.

${ }^{68}$ Michels RG: A clinical and histopathological study of epiretinal membranes affecting the macula and removed by vitreous surgery. Trans. Am. Ophthalmol. Soc. 1982; 80: 580-656.

${ }^{69}$ Barry PJ, Hiscott PS, Grierson I, Marshall J, McLeod D: Reparative epiretinal fibrosis after diabetic vitrectomy. Trans. Ophthalmol. Soc. UK. 1985; 104: 285-96.

${ }^{70}$ Novak MA, Rice TA, Michels RG, Auer C: The crystalline lens after vitrectomy for diabetic retinopathy. Ophthalmology 1986; 93: 602-10. 